\title{
Treatment adherence and perception in patients on maintenance hemodialysis: a cross - sectional study from Palestine
}

Karam Sh. Naalweh', Mohammad A. Barakat', Moutaz W. Sweileh', Samah W. Al-Jabi², Waleed M. Sweileh³ and Sa'ed H. Zyoud ${ }^{2,4^{*}}$ (i)

\begin{abstract}
Background: Adherence to diet recommendations, fluid restriction, prescribed medications, and attendance at hemodialysis (HD) sessions are essential for optimal and effective treatment of patients with end-stage renal disease. No data regarding this issue are available from Palestine. Therefore, this study was carried out to assess adherence to diet, fluid restriction, medications, and HD sessions.
\end{abstract}

Methods: A cross-sectional study of HD patients at An-Najah National University Hospital was carried out during summer, 2016. Self-reported adherence behavior was obtained using a valid and reliable questionnaire (End-Stage Renal Disease Adherence Questionnaire: ESRD-AQ). Predialytic serum levels of potassium and phosphate were obtained as clinical indicator of diet and medication adherence respectively. In addition, interdialytic body weight (IDW) was also obtained from medical records and analyzed in relation to reported adherence of fluid restriction.

Results: A total of 220 patients answered all questions pertaining to ESRD-AQ. The mean age \pm standard deviation of participants was $56.82 \pm 14.51$ years. Dietary adherence was observed in $24 \%$ while that of fluid restriction adherence was observed in 31\% of studied patients. Reported adherence to HD sessions was $52 \%$ while that for medications was 81\%. Overall, 122 (55.5\%) patients had good adherence, 89 (40.5\%) had moderate adherence, and $9(4.1 \%)$ had poor adherence behavior. Male patients had significantly higher overall adherence scores than females $(p=0.034)$. A significant correlation between reported diet adherence and serum pre-HD potassium level $(p<0.01)$ was observed. A significant correlation between reported fluid restriction adherence and IDW $(p<0.01)$ was also found. However, no significant correlation between reported adherence and pre-HD phosphate level. There was significant correlation between overall perception and overall adherence score $(p<0.001)$. Counselling of patients regarding importance of adherence modalities was lowest for "staying for the entire dialysis time". Multivariate analysis indicated that elderly male patients who were city residents had higher odds of having higher adherence score.

Conclusions: There was a good percentage of patients who had overall moderate or poor adherence. ESRDAQ could be used to assess some aspects of HD adherence. Counselling and education of patients on HD are important to improve therapeutic outcome.

Keywords: Hemodialysis, Treatment adherence, Perception, Clinical outcomes, Palestine

\footnotetext{
* Correspondence: saedzyoud@yahoo.com; saedzyoud@najah.edu

${ }^{2}$ Division of Clinical and Community Pharmacy, Department of Pharmacy, College of Medicine and Health Sciences, An-Najah National University, Nablus 44839, Palestine

${ }^{4}$ Poison Control and Drug Information Center (PCDIC), College of Medicine and Health Sciences, An-Najah National University, Nablus 44839, Palestine Full list of author information is available at the end of the article
} 


\section{Background}

Chronic kidney disease (CKD) is a progressive irreversible structural damage and/ or kidney function [1]. There are five categories of CKD in which stage 5 (End Stage Renal Disease (ESRD)) is the last and most serious stage [1]. In patients with ESRD, renal replacement therapy (RRT) such as long-term dialysis or kidney transplantation is needed for survival $[2,3]$. Kidney transplantation is the best choice for management of patients with ESRD $[4,5]$. However, the limited availability of organ donors made hemodialysis (HD) procedure as most efficient and practical method for management of patients with ESRD [6].

Patients on long-term HD are considered partially responsible for the success of their therapy by adherence to medication prescription, adherence to diet and fluid restrictions and complete adherence to HD sessions [7]. Failure of adherence in HD patients can lead to increase morbidity, mortality, cost, and burden on healthcare system [8-12]. Patients undergoing HD are required to maintain their potassium and phosphate serum level within a safe range to avoid serious complications such as fatal arrhythmia and osteodystrophy [13]. Furthermore, they are also required to maintain a limited amount of fluid intake to avoid edema and cardiovascular complications [13]. Several reports on adherence among HD patients have been published [11, 14-17]. Many other published studies reported lack of diet and medication adherence among patients undergoing HD [17-21]. Despite the importance of adherence in general population of patients and in HD patients in particular, there are very limited number of studies which discussed this topic at the local and regional level in Arab countries [22-24]. In Palestine, there are few studies on medication adherence in general and none about adherence in HD patients [25-33].

In Palestine, the majority patients with ESRD are treated as chronic HD patients in hospitals run by the Palestinian government which suffers from continuous financial problems and limited economic resources [34, 35]. It has been reported that risk factors for non-adherence includes health care system-related factors which have been neglected by most authors who assessed the subject $[7,36]$. Since the healthcare system in Palestine and in the Arab region is different from that in the USA, Europe and in other developed countries, this necessitates the assessment of adherence among HD patients in Palestine and implementing the necessary changes and measures to overcome such a problem. Few years ago, the Palestinian Ministry of Health made an agreement with An-Najah National University Hospital in Nablus to carry out HD procedure for patients with governmental insurance in Nablus district. Currently, AnNajah National University Hospital provides nephrology services for approximately 220 patients with ESRD living in Nablus district. The hospital is equipped with up-todate technology and has specialized and well - trained staff.

Assessing adherence among HD patients will allow healthcare providers to implement interventional methods to minimize health and economic consequences of nonadherence. The aim of this study was to assess extent of adherence among HD patients to different treatment modalities. The study was carried on patients attending HD center at An-Najah National University Hospital. In specific, the current study will assess adherence to fluid restriction, adherence to diet recommendations, adherence to medications, and adherence to HD schedules.

\section{Methods}

This study was conducted in the main HD center in northern west-bank located at An-Najah National University Hospital in Nablus. The center offers HD services to a total population of more than 100,000 people living in Nablus district. The study included all patients $\geq 18$ years of age who were conscious, have been on $\mathrm{HD}$ for at least 6 months, receive dialysis at least twice weekly with a minimum of $3 \mathrm{~h}$ per session, and his/her medical file contained all needed biochemical, clinical, and demographic information needed for this study. The study was cross-sectional and was carried out during the summer of 2016. For this study, all patients attending the HD unit were approached and asked to participate in the study. To achieve this, three of the co-authors spent 6 consecutive weeks at the dialysis center for the purpose of data collection. The three co-authors were senior medical students who were trained on the tool used to assess adherence. One co-author did the interviews and two co-authors collected information pertaining to biochemical and clinical information from medical files of interviewed patients. Patients included in the study were asked to give an informed consent based on the Institutional Review Board (IRB) approval of the study.

In this study, the ESRD-AQ (End Stage Renal Disease Adherence Questionnaire) was used as a tool to assess: (1) degree of adherence, (2) perception, and (3) counselling of patients toward HD treatment modalities. The ESRD-AQ is a reliable and valid instrument used to assess adherence among HD patients [37]. The questionnaire consists of 46 items that were distributed into five sections: the first section contained general and history related information while the remaining four sections measures adherence to HD sessions, adherence to medications, adherence to fluid restriction, and adherence to diet recommendations. Questions number 14, 17, 18, 26, 31, and 46 were used to calculate the adherence behavior subscale. These questions were scored and response of patients to these questions was summed to calculate 
the adherence behavior subscale. According to ESRD$\mathrm{AQ}$, higher scores represents higher adherence to the measured behavior.

Questions number 11, 12, 22, 23, 32, 33, 41, and 42 were used to assess and describe the attitude/perception subscale. These questions were non-scored but the answers range from very high (given number 1 ) to very low (given number 5) with the possibility of presenting answers in a numerical way. In adherence subscale, higher scores indicate better adherence. For the clinical assessment of adherence, pre-dialytic serum potassium and phosphate levels were used along with interdialytic body weight (IDW) as clinical indicators for adherence to diet, adherence to medications, and adherence to fluid restriction respectively.

For the purpose of this study, the ESRD-AQ scale was translated into Arabic by two colleagues who are USA graduates with Arabic being their native language. Then the translated scale was back translated to English and compared by the authors with original copy to make sure that none of the questions lost any of its intended meaning. The Arabic - translated ESRD-AQ was not validated although the original English version of ESRDAQ was validated. The Arabic - translated version of the ESRD-AQ is provided in Additional file 1.

Measured clinical outcomes included biochemical markers of pre-HD serum phosphorus and potassium. Mean \pm standard deviation of pre-HD serum potassium level was used as a biochemical marker for adherence to diet recommendation while mean value for pre-HD serum phosphate level was used as a biochemical marker for medication (phosphate binders, i.e. calcium carbonate) adherence. For all biochemical markers, average of the last three measurements carried out in the past month was used. Finally, the IDW was calculated by subtracting the post-HD weight from the pre-HD weight which represents fluid consumption from one dialysis session to the next. The mean of three consecutive IDW was used as a biochemical marker for fluid restriction adherence.

\section{Statistical analysis}

Statistical Package for Social Sciences version 16 (SPSS Inc., Chicago, IL, USA) was used for data processing. Mean \pm standard deviation and/ or median (first quartile - third quartile) were used to describe data after checking for normality of data which was tested using Kolmogorov test. Correlations between variables were tested using Spearman correlation and both significance $(p)$ and correlation coefficient $(r)$ were presented whenever appropriate. Comparison of adherence between males and females was carried out using Mann - Whitney U test. Predictors of adherence were obtained by using multiple linear regression. The independent factors used in the model were gender, marital status, residency, living status, type of transportation to HD centre, and the duration of illness (ESRD). These were all demographic and clinical variables obtained directly from studied patients. The significance level was predetermined at $\mathrm{p}$ level $<$ of 0.05 for all tests.

\section{Results \\ General information}

A total of 223 met the inclusion criteria and were recruited for the study. However three patients died during the study period and were excluded from analysis. Therefore, a total of 220 patients were recruited and interviewed. The total number of patients recruited represented $98.65 \%$ of eligible patients at the time of study. Studied patients had a mean age of $56.82 \pm 14.51$ years with a range of $18-85$ years. More than two thirds of studied patients $(159,72.3 \%)$ were under 65 years of age. The majority of studied sample were males $(128,58.2 \%)$, married (189, 85.9\%), and city residents (102, 46.4\%). Approximately one third $(74 ; 33.64 \%)$ of studied patients were diabetic hypertensive, 122 (55.46\%) had hypertension and 87 (39.55\%) patients had diabetes mellitus (DM). A total of 136 (61.82\%) of studied patients had either DM, or hypertension or both. A total of 85 (38.6\%) patients had no chronic diseases as a known cause of ESRD. Twenty patients (9.1\%) had previous kidney transplant. Approximately two thirds (149.67.7\%) of the patients used public transportation to reach the dialysis center and the majority $(102,46.4 \%)$ attended the dialysis sessions alone without any family company. The majority of studied patients $(203,92.27 \%)$ described their dialysis schedule as convenient. The mean number of months of dialysis as reported by studied patients was $48.16 \pm 44.41$ with a range of $12-408$ months. Table 1 shows selected socio-demographic and clinical characteristics of the study sample.

\section{Specific and overall adherence}

Adherence to the four treatment modalities was assessed. Adherence to HD sessions was the highest with an average score of $296.36 \pm 26.78$ out of a maximum score of 300. Adherence to medications was also assessed and the mean score was $184.32 \pm 37.83$ out of a maximum score of 200. Mean adherence score for fluid restriction was $140.68 \pm 53.78$ out of a maximum score of 200. Mean adherence score to diet recommendations was $134.55 \pm 52.01$ out of a maximum score of 200 (Table 2).

Overall adherence behavior of each patient was assessed by summing the scores of questions 14, 17, 18, 26, 31, and 46. A total of 122 (55.5\%) patients had good overall adherence behavior, 89 (40.5\%) had moderate adherence and nine patients $(4.1 \%)$ had poor adherence (Table 3). There was no statistically significant correlation 
Table 1 Selected socio-demographic and clinical characteristics of the study sample

\begin{tabular}{|c|c|}
\hline Variable & $\begin{array}{l}\text { Mean } \pm \text { SD or number } \\
\text { of patients (\%) }\end{array}$ \\
\hline Age (mean \pm SD) & $56.82 \pm 14.51$ \\
\hline \multicolumn{2}{|l|}{ Gender } \\
\hline $\begin{array}{l}\text { Male } \\
\text { Female }\end{array}$ & $\begin{array}{l}128(58.2) \\
92(41.8)\end{array}$ \\
\hline \multicolumn{2}{|l|}{ Marital status } \\
\hline $\begin{array}{l}\text { Married } \\
\text { Single/widowed/divorced }\end{array}$ & $\begin{array}{l}189(85.9) \\
31(14.1)\end{array}$ \\
\hline \multicolumn{2}{|l|}{ Education level } \\
\hline $\begin{array}{l}\leq \text { High school } \\
\geq \text { College/university }\end{array}$ & $\begin{array}{l}208(94.5) \\
12(5.5)\end{array}$ \\
\hline \multicolumn{2}{|l|}{ Residency } \\
\hline $\begin{array}{l}\text { City } \\
\text { Suburbs (Palestinian refugee } \\
\text { camps or village) }\end{array}$ & $\begin{array}{l}102(46.4) \\
118(53.6)\end{array}$ \\
\hline Duration of dialysis (mean \pm SD) months & $48.2 \pm 44.4$ \\
\hline \multicolumn{2}{|l|}{ Diabetes mellitus } \\
\hline $\begin{array}{l}\text { Yes } \\
\text { No }\end{array}$ & $\begin{array}{l}87(39.6) \\
133(60.4)\end{array}$ \\
\hline \multicolumn{2}{|l|}{ Hypertension } \\
\hline $\begin{array}{l}\text { Yes } \\
\text { No }\end{array}$ & $\begin{array}{l}122(55.5) \\
98(44.5)\end{array}$ \\
\hline \multicolumn{2}{|l|}{ Diabetes mellitus and hypertension } \\
\hline $\begin{array}{l}\text { Yes } \\
\text { No }\end{array}$ & $\begin{array}{l}74(33.6) \\
146(66.4)\end{array}$ \\
\hline \multicolumn{2}{|l|}{ Kidney transplant } \\
\hline $\begin{array}{l}\text { Yes } \\
\text { No }\end{array}$ & $\begin{array}{l}20(9.1) \\
200(91.9)\end{array}$ \\
\hline \multicolumn{2}{|l|}{ How he/she reached the center } \\
\hline $\begin{array}{l}\text { Public transportation } \\
\text { Private/ others (ambulance) }\end{array}$ & $\begin{array}{l}152(69.1) \\
68(30.9)\end{array}$ \\
\hline \multicolumn{2}{|l|}{ Accompanied by family to HD center } \\
\hline $\begin{array}{l}\text { Yes } \\
\text { No (Alone) }\end{array}$ & $\begin{array}{l}118(53.6) \\
102(46.4)\end{array}$ \\
\hline
\end{tabular}

Abbreviations: $S D$ Slandered deviation, $H D$, hemodialysis between adherence behavior and age (Spearman correlation: $p=0.27, r=0.074$ ) or number of months since starting (Spearman correlation: $p=0.98, r=-0.002$ ). However, male patients had significantly higher adherence behavior score compared to female patients $($ male $=1003.13 \pm 144.18 ;$ female $=960.60 \pm 154.74$; $p=0.034)$.

\section{Clinical outcomes}

The mean \pm SD for pre-HD serum potassium of studied patients was $1.27 \pm 0.19 \mathrm{meq} / \mathrm{l}$ while the median $(\mathrm{Q} 1-\mathrm{Q} 3)$ was $1.28(1.13-1.41) \mathrm{meq} / \mathrm{l}$. There was a significant negative correlation between pre-dialytic serum potassium level and diet adherence score (Spearman correlation: $p<0.001 ; r=-0.28)$. The mean IDW was $3.10 \pm 1.63 \mathrm{Kg}$ while the median (Q1-Q3) was $3.0(2-4) \mathrm{Kg}$. There was a significant negative correlation between IDW and adherence to fluid restriction (Spearman correlation: $p<0.001$, $r=-0.423$ ). The mean (SD) pre-dialytic phosphate level was $1.56 \pm 0.54$ while the median $(\mathrm{Q} 1-\mathrm{Q} 3)$ was 1.51 $(1.28-1.76) \mathrm{meq} / \mathrm{L}$. The levels of serum phosphate are within high normal level indicative of denutrition. There was no significant correlation between medication adherence and pre-dialytic phosphorous level (Spearman correlation: $p=0.29$ ) (Tables 4 and 5).

A significant correlation between pre-dialytic serum potassium level and total adherence behavior score $(p=0.028, r=-0.15)$ was found. Similarly, a significant correlation between IDW and adherence behavior score $(p<0.001, r=0.37)$ was found. However, no significant correlation between phosphate and total adherence behavior score was found. No significant correlation was found between total number of dialysis hours per week in one hand and any of the treatment modalities on the other hand.

\section{Perception of patients toward various HD treatment modalities}

We assessed the perception of studied patients toward various HD treatment modalities (Table 6). Perception toward HD sessions had the highest score with $96.4 \%$ of studied patients believe that it is highly/very important to follow the dialysis schedule. Perception toward diet

Table 2 Mean (SD) adherence score for various treatment modalities

\begin{tabular}{llll}
\hline Item \# in ESRD-AQ & Adherence & Range of score & Mean score (SD) \\
\hline 14 & HD - attendance & $100-300$ & 296.36 (26.78) \\
17 & Episode of shortening HD & $0-200$ & $149.32(68.83)$ \\
18 & Duration of shortening HD if shortened & $0-100$ & $80.11(27.54)$ \\
26 & Adherence to medication & $0-200$ & $184.32(37.83)$ \\
31 & Adherence to fluid restriction & $0-200$ & $140.68(53.78)$ \\
46 & Adherence to dietary restriction & $0-200$ & $134.55(52.01)$ \\
\hline
\end{tabular}

Abbreviations: SD Slandered deviation, $H D$ hemodialysis, ESRD-AQ End-Stage Renal Disease Adherence Questionnaire 
Table 3 Overall adherence and End-Stage Renal Disease Adherence Questionnaire (ESRD-AQ) score

\begin{tabular}{llll}
\hline Adherence category & Total Score & Frequency & Percent \\
\hline Poor & $<700$ & 9 & 4.1 \\
Moderate & $700-999$ & 89 & 40.5 \\
Good & $1000-1200$ & 122 & 55.5 \\
\hline
\end{tabular}

restriction was the lowest with $77.7 \%$ of studied patients believe that it is highly/ very important to watch the type of food taken daily. The perception of importance toward medication adherence and fluid restriction were comparatively fair with $85.5 \%$ and $88.6 \%$ of the studied patients believe that it is highly/very important to adhere to medications and restrict fluid intake respectively.

The sum of perception scores obtained by summing questions 11, 22, 32 and 41 yielded a median of 6 (Q1$\mathrm{Q} 3=5-8)$ and a mean of a $6.86 \pm 2.39$. Of course the lower the total score of perception, the better attitude the patients had toward HD treatment modalities. Spearman correlation between total perception score and total adherence score yielded a significant negative correlation $(p<0.001, r=-0.446)$ suggesting that better perception and attitude yields better adherence score.

\section{Counselling}

Eight items in the ESRD-AQ discuss the counselling received by patients for various treatment modalities. For each treatment modality, the patients were asked two questions pertaining to counseling. The most negative answer was "never". Approximately $42 \%$ of studied patients reported that they had never been talked to by a healthcare provider about "the importance of staying for the entire dialysis time during dialysis treatment". Regarding medication counselling, approximately $21 \%$ of studied patients reported that they had never been talked to by a healthcare provider regarding their medications. Similarly,
19\% reported that they had never been talked to by a healthcare provider regarding the importance of following a diet restriction. The counselling for other treatment modalities is shown in Fig. 1.

\section{Predictors of adherence}

Multivariate analysis indicated significant association between a number of independent variables and adherence score in comparison to a reference category for categorical variables or with one unit increase for a continuous variable. Age, gender, and residence were positively associated with adherence scores. In specific, elderly male patients who lives in the city have higher odds of having higher overall adherence score (Table 7).

\section{Discussion}

In the current study, adherence behaviors among patients on maintenance HD were investigated and analyzed. The findings of our study showed that adherence to HD treatment modalities was less than optimum with approximately $45 \%$ of studied patients had an overall moderate or poor adherence. A significant correlation between reported diet adherence and pre-HD serum potassium level is suggestive of the validity of reported adherence scores. Similar significant correlation existed between reported fluid restriction adherence and IDW. Our study showed that perception of importance of adherence was significantly correlated with reported adherence suggesting that counselling of patients on HD regarding their treatment modalities is important to improve therapeutic outcome. Our study indicated that male elderly patients who live in the city have higher odds of having higher adherence.

From a health point of view, the majority of patients (55\%) were hypertensive and 39\% were diabetic patients. A study carried out in Saudi Arabia found that most of HD patients were diagnosed with hypertension and

Table 4 Correlations between reported adherence and clinical outcomes

\begin{tabular}{|c|c|c|c|c|c|}
\hline Variables $^{a}$ & $\begin{array}{l}\text { Pre-dialysis Phosphate } \\
\text { level }\end{array}$ & $\begin{array}{l}\text { Pre-dialysis Potassium } \\
\text { level }\end{array}$ & IDW & $\begin{array}{l}\text { Diet adherence } \\
\text { score }\end{array}$ & $\begin{array}{l}\text { Fluid restriction } \\
\text { adherence score }\end{array}$ \\
\hline \multirow[t]{2}{*}{ Pre-dialysis Potassium level } & .331 & & & & \\
\hline & $<0.001^{b}$ & & & & \\
\hline \multirow[t]{2}{*}{ IDW } & .137 & .210 & & & \\
\hline & $0.042^{b}$ & $0.002^{b}$ & & & \\
\hline \multirow[t]{2}{*}{ Diet adherence score } & -.108 & -.281 & -.270 & & \\
\hline & .110 & $<0.001^{b}$ & $<0.001^{b}$ & & \\
\hline \multirow[t]{2}{*}{ Fluid restriction adherence score } & -.081 & -.128 & -.423 & .408 & \\
\hline & .229 & .058 & $<0.001^{b}$ & $<0.001^{\mathrm{b}}$ & \\
\hline \multirow[t]{2}{*}{ Medication adherence score } & .071 & .042 & -.143 & .004 & .043 \\
\hline & .292 & .540 & $0.035^{\mathrm{b}}$ & .954 & .526 \\
\hline
\end{tabular}

${ }^{a}$ For each pair of correlation, the number in the top cell represents the Spearman correlation value while the number in the bottom cell represents the significance level

${ }^{\mathrm{b}}$ The $p$-values are bold where they are less than the significance level cut-off of 0.05 
Table 5 Summary of correlation results

\begin{tabular}{ll}
\hline Correlation & Result \\
\hline Potassium and adherence to diet recommendation & Significant \\
Potassium and adherence to fluid restriction & Significant \\
Potassium and medication adherence & Not significant \\
IDW and adherence to diet recommendation & Significant \\
IDW and adherence to fluid restriction & Significant \\
IDW and medication adherence & Not Significant \\
Phosphate and adherence to diet recommendation & Not Significant \\
Phosphate and adherence to fluid restriction & Not Significant \\
Phosphate and medication adherence & Not Significant \\
\hline
\end{tabular}

more than one third were diagnosed with DM. A study carried out in India found that $81 \%$ of HD patients were hypertensive and $24 \%$ were diabetics. Differences in comorbid diseases among patients with HD in various studies are probably due to differences in ethnic and cultural environment of the study sample. It should be emphasized that patients in our study were homogenous; all patients were Palestinians from one district which is in contrast to studied sample in other studies where patients had different ethnic background.

In our study, there was a significant correlation between reported adherence to fluids or dietary recommendation and clinically determined adherence. This suggests that reported fluid or diet adherence calculated by ESRD-AQ is trustful given the significant correlation with clinically determined adherence parameters. However, no significant correlation between pre-dialytic serum phosphate with any reported adherence behavior was found. This suggests that ESRD-AQ might not be a good tool to assess medication adherence or that pre-dialytic phosphate serum level was not a suitable clinical indicator for reported medication adherence among studied patients. Actually, medications for HD patients are dispensed in a complex manner that might make their answers to medication adherence inaccurate. Studied patients receive HD at An-Najah National University Hospital and receive their medications from governmental pharmacies since they are covered by governmental insurance. Furthermore, patients sometimes fail to adhere to medications simply because medications are not always available at the hospital. So, despite the fact that a patient might perceive himself/herself as fully adherent, he/she might not be taking their medications because the medications were not dispensed due to lack of medications.

Results obtained from various studies on adherence among HD patients vary widely which made comparison among different studies a difficult task. Several studies were published from different world regions regarding prevalence of treatment adherence among HD patients. A study in Malaysia found that rates of adherence to fluid, dietary, medication, and dialysis were $27.7,66.5$, 24.5, and 91.0\%, respectively [38]. A study in Makah city found that the prevalence of adherence to fluid restrictions recommendations, dietary, and medication prescription among HD patients were 87.78, 88.37, and $87.99 \%$, respectively [39]. Nearly half of patients reported in Makah study were adherent to dialysis sessions (55.96\%) [39]. A study in China in HD patients found that fluid and dietary adherence were seen in $40.3 \%$ and $35.5 \%$ respectively [40].

In our study, it was noticed that adherence to HD attendance, mainly shortening of HD sessions, was relatively low. In this regard, it seems that patients have been poorly counseled regarding completing HD sessions since almost $42 \%$ of patients reported that they have never been counseled in this regard. It seems that patients' education and counselling are important in formulating patients' general perception toward various treatment aspects which in turn can significantly affect patients' adherence. In this study, counselling regarding medications and diet restriction were not high which in turn created relatively lower perception toward various treatment aspects among studied patients.

Our study showed that older patients and male patients have higher odds of being adherent. Some studies showed similar findings regarding age but found no effect of gender on level of adherence [22, 41]. In contrast to the finding presented in our study, marital status was found to be

Table 6 Perception on importance of adherence to various treatment modalities

\begin{tabular}{lllll}
\hline Item \# in ESRD-AQ & Perception on importance & $\begin{array}{l}\text { Highly/Nery important } \\
n(\%)\end{array}$ & $\begin{array}{l}\text { Moderately important } \\
n(\%)\end{array}$ & $\begin{array}{l}\text { Little/Not important } \\
n(\%)\end{array}$ \\
\hline 11 & $\begin{array}{l}\text { How important do you think it is to follow your } \\
\text { dialysis schedule? }\end{array}$ & $212(96.3)$ & $2(2.7)$ & $22(10)$ \\
22 & $\begin{array}{l}\text { How important do you think it is to take your } \\
\text { medicines as scheduled? }\end{array}$ & $188(85.5)$ & $17(7.7)$ & $8(3.7)$ \\
32 & $\begin{array}{l}\text { How important do you think it is to limit your } \\
\text { fluid intake? }\end{array}$ & $195(88.6)$ & $29(13.2)$ & $20(9.1)$ \\
41 & How important do you think it is important for & $171(77.7)$ & &
\end{tabular}




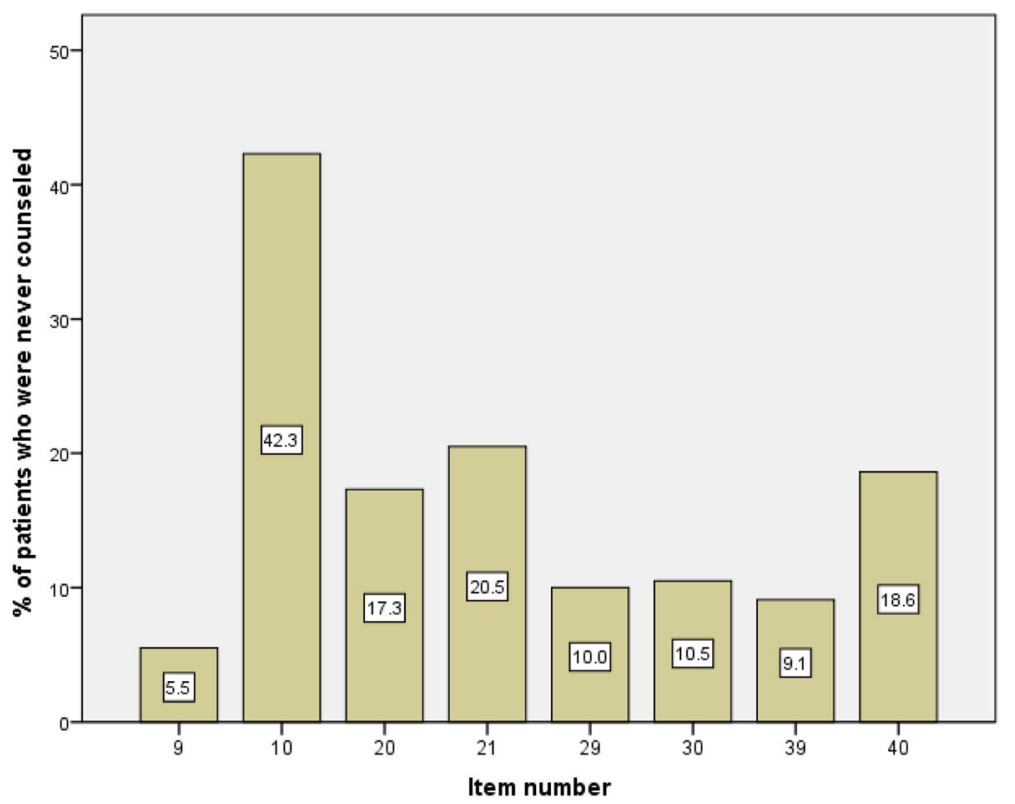

Fig. 1 Percentage of patients who were never counseled regarding different treatment modalities. Item \# 9: When was the last time a medical professional (your doctor, nurse, dietician, or other medical staff) talked to you about the importance of not missing your dialysis treatment? Item \# 10: How often does a medical professional (your doctor, nurse, dietician, or other medical staff) talk to you about the importance of staying for the entire dialysis time during your dialysis treatment? Item \# 20: When was the last time a medical professional (your doctor, nurse, dietician or other medical staff) spoke to you about your medicines? Item \# 21: How often does a medical professional (your doctor, nurse, dietician or other medical staff) talk to you about the importance of taking medicines as ordered? Item \# 39: When was last time a medical professional (your doctor, nurse, dietician, or other medical staff) talked to you about your diet? Item \# 40: How often does a medical professional (your doctor, nurse, dietician or other medical staff) talk to you about the importance of following a proper diet?

Table 7 Multiple linear regression analysis of association between factors and adherence score

\begin{tabular}{|c|c|c|c|c|}
\hline Variables & Unstandardised coefficients (B) & Standardised coefficients (Beta) & $P$ value $^{a}$ & $95 \% \mathrm{Cl}$ for $\mathrm{B}$ \\
\hline \multicolumn{5}{|l|}{ Age } \\
\hline Continuous (1-year units) & 1.78 & 0.17 & 0.021 & $0.28-3.29$ \\
\hline \multicolumn{5}{|l|}{ Gender } \\
\hline $\begin{array}{l}\text { Male } \\
\text { Female }\end{array}$ & $\begin{array}{l}44.88 \\
\text { Reference }\end{array}$ & 0.15 & 0.038 & $2.58-87.17$ \\
\hline \multicolumn{5}{|l|}{ Marital status } \\
\hline $\begin{array}{l}\text { Married } \\
\text { Widowed /divorced }\end{array}$ & $\begin{array}{l}26.11 \\
\text { Reference }\end{array}$ & -0.06 & 0.431 & $-91.29-39.07$ \\
\hline \multicolumn{5}{|l|}{ Residency } \\
\hline $\begin{array}{l}\text { City } \\
\text { Palestinian refugee camps or village }\end{array}$ & $\begin{array}{l}51.32 \\
\text { Reference }\end{array}$ & 0.17 & 0.015 & $9.89-92.75$ \\
\hline \multicolumn{5}{|l|}{ Duration of dialysis } \\
\hline Continuous (1-month units) & 0.14 & 0.04 & 0.615 & $-0.41-0.69$ \\
\hline \multicolumn{5}{|l|}{ Dialysis centre transportation } \\
\hline $\begin{array}{l}\text { Public transportation } \\
\text { Private/ ambulance }\end{array}$ & $\begin{array}{l}18.39 \\
\text { Reference }\end{array}$ & -0.06 & 0.402 & $-61.59-24.80$ \\
\hline \multicolumn{5}{|l|}{ Living statues } \\
\hline $\begin{array}{l}\text { With family } \\
\text { Alone }\end{array}$ & $\begin{array}{l}-0.13 \\
\text { Reference }\end{array}$ & 0.00 & 0.995 & $-43.53-43.27$ \\
\hline
\end{tabular}


a detrimental factor for adherence [42]. In our study, the level of education was not entered in the regression model since the vast majority of the study sample had the same level of school education and a small minority had college or university education. Other studies have found a positive role of education on level of adherence [7].

Our study had a few limitations that are inherent to the nature of the study design and the self-reported approach of the tool used in the study. Reports indicated that there is a disagreement between self-reported adherence and actual/observed adherence [43, 44]. A second limitation of our study is the lack of validated Arabic-translated version of the ESRD-AQ scale. A third limitation is the absence of a universally accepted cutoff value for each biological marker to be a valid point for identification of adherent versus non-adherent patients. Therefore, the validity of these biological markers to assess adherence in ESRD patients might be questionable although these markers may be more effective or reliable measures of clinical outcomes but not necessarily be adequate for measuring non-adherence. Finally, our study was a single center study and we hope that future research will be designed to include all HD patients in Palestine.

\section{Conclusions}

Our study showed that adherence to HD treatment modalities is less than optimum. Approximately $45 \%$ of studies patients had overall moderate or poor adherence. A significant correlation between reported diet adherence and pre-HD serum potassium level is suggestive of the validity of reported adherence scores. Similar significant correlation existed between reported fluid restriction adherence and IDW. Our study showed that perception of importance of adherence is significantly correlated with reported adherence suggesting that counselling and education of patients on HD regarding their treatment modalities is important to improve therapeutic outcome. Finally, male older patients who were city residents had higher odds of being more adherent.

\section{Additional file}

Additional file 1: Arabic version of ESRD-AQ. This file is the Arabic translated version of ESRD-AQ scale used in the current study. The translation process is explained in the methodology section. (DOC $90 \mathrm{~kb}$ )

\section{Abbreviations}

CKD: Chronic kidney disease; DM: Diabetes mellitus; ESRD: End Stage Renal Disease; ESRD-AQ: End-Stage Renal Disease Adherence Questionnaire; IDW: Inter-dialytic body weight; IRB: Institutional Review Board; RRT: Renal replacement therapy; SPSS: Statistical Package for Social Sciences

\section{Acknowledgments}

The authors would like to acknowledge An-Najah National University and An-Najah National University hospital for giving us the opportunity to carry out this project.

\section{Funding}

This project did not receive any type of financial funding throughout all stages of the project. No funding of any type was received for planning the project or data collection or data analysis or writing the manuscript or submission of the manuscript.

\section{Availability of data and materials}

The raw data supporting the findings presented in the current study will be available from the corresponding author upon request.

\section{Authors' contributions}

$\mathrm{KN}, \mathrm{MB}$, and MS collected data, performed the analyses and literature search, and drafted the manuscript. SZ, SA, and WS conceptualized and designed the study, and assisted in final write-up of the manuscript and revised the manuscript. Then all read, and approved the final manuscript.

\section{Competing interests}

The authors declare that they have no competing interests.

\section{Consent for publication}

Not applicable.

\section{Ethics approval and consent to participate}

This study was approved by An-Najah National University Institutional Review Board and by An-Najah National University Hospital Administration. Approval was obtained before the start of the study. Approval was obtained on April 2016 from the IRB office at College of Medicine at An-Najah National University. Patients included in the study were asked to give an informed consent before the start of the interview. All patients agreed to the anonymous use of their clinical data for research purposes

\section{Publisher's Note}

Springer Nature remains neutral with regard to jurisdictional claims in published maps and institutional affiliations.

\section{Author details}

${ }^{1}$ Department of Medicine, College of Medicine and Health Sciences, An-Najah National University, Nablus 44839, Palestine. ${ }^{2}$ Division of Clinical and Community Pharmacy, Department of Pharmacy, College of Medicine and Health Sciences, An-Najah National University, Nablus 44839, Palestine. ${ }^{3}$ Department of Pharmacology and Toxicology, College of Medicine and Health Sciences, An-Najah National University, Nablus 44839, Palestine. ${ }^{4}$ Poison Control and Drug Information Center (PCDIC), College of Medicine and Health Sciences, An-Najah National University, Nablus 44839, Palestine.

Received: 14 October 2016 Accepted: 19 May 2017

Published online: 30 May 2017

References

1. Kidney Disease: Improving Global Outcomes (KDIGO) CKD Work Group: KDIGO. 2012 clinical practice guideline for the evaluation and management of chronic kidney disease. Kidney Int Suppl. 2013(3):1-150.

2. Laupacis A, Keown P, Pus N, Krueger H, Ferguson B, Wong C, et al. A study of the quality of life and cost-utility of renal transplantation. Kidney Int. 1996;50(1):235-42.

3. El Nahas M. The global challenge of chronic kidney disease. Kidney Int. 2005;68(6):2918-29.

4. Abecassis M, Bartlett ST, Collins AJ, Davis CL, Delmonico FL, Friedewald JJ, et al. Kidney transplantation as primary therapy for end-stage renal disease: a National Kidney Foundation/Kidney Disease Outcomes Quality Initiative (NKF/KDOQI IM) conference. Clin J Am Soc Nephrol. 2008;3(2):471-80.

5. Kaza BNK, Sabi KA, Amekoudi EYM, Imangue G, Al-Torayhi MH, Tsevi CM, et al. Kidney transplantation: Hemodialysis and surrounding are they informed enough? Indian J Transplant. 2015;9(3):101-4.

6. Smith JM. Kidney transplantation: only for the well-to-do? Campbell Law Rev. 2008;31:333-59. 
7. Kugler C, Maeding I, Russell CL. Non-adherence in patients on chronic hemodialysis: an international comparison study. J Nephrol. 2011;24(3):366-75.

8. Walser M. Is there a role for protein restriction in the treatment of chronic renal failure? Blood Purif. 2000;18(4):304-12.

9. Unruh ML, Evans IV, Fink NE, Powe NR, Meyer KB. Skipped treatments, markers of nutritional nonadherence, and survival among incident hemodialysis patients. Am J Kidney Dis. 2005;46(6):1107-16.

10. Tentori F, Hunt WC, Rohrscheib M, Zhu M, Stidley CA, Servilla K, et al. Which targets in clinical practice guidelines are associated with improved survival in a large dialysis organization? J Am Soc Nephrol. 2007;18(8):2377-84.

11. Bame SI, Petersen N, Wray NP. Variation in hemodialysis patient compliance according to demographic characteristics. Soc Sci Med. 1993;37(8):1035-43.

12. Shirazian S, Crnosija N, Weinger K, Jacobson AM, Park J, Tanenbaum ML, et al. The self-management experience of patients with type 2 diabetes and chronic kidney disease: a qualitative study. Chronic IIIn. 2016;12(1):18-28.

13. South African Renal Society. Guidelines for the optimal care of patients on chronic dialysis in South Africa. 2006 [cited 2016]; Available from: http:// www.kznhealth.gov.za/medicine/sars.pdf

14. Leggat JE Jr, Orzol SM, Hulbert-Shearon TE, Golper TA, Jones CA, Held PJ, et al. Noncompliance in hemodialysis: predictors and survival analysis. Am J Kidney Dis. 1998;32(1):139-45.

15. Ashurst Ide $B$, Dobbie $H$. A randomized controlled trial of an educational intervention to improve phosphate levels in hemodialysis patients. J Ren Nutr. 2003;13(4):267-74.

16. Sharp J, Wild MR, Gumley Al, Deighan CJ. A cognitive behavioral group approach to enhance adherence to hemodialysis fluid restrictions: a randomized controlled trial. Am J Kidney Dis. 2005;45(6):1046-57.

17. Denhaerynck K, Manhaeve D, Dobbels F, Garzoni D, Nolte C, De Geest S. Prevalence and consequences of nonadherence to hemodialysis regimens. Am J Crit Care. 2007;16(3):222-35. quiz 236

18. Christensen AJ, Ehlers SL. Psychological factors in end-stage renal disease: an emerging context for behavioral medicine research. J Consult Clin Psychol. 2002;70(3):712-24.

19. Wolcott DL, Maida CA, Diamond R, Nissenson AR. Treatment compliance in end-stage renal disease patients on dialysis. Am J Nephrol. 1986;6(5):329-38.

20. Kaveh K, Kimmel PL. Compliance in hemodialysis patients: multidimensional measures in search of a gold standard. Am J Kidney Dis. 2001;37(2):244-66.

21. Clark S, Farrington $\mathrm{K}$, Chilcot J. Nonadherence in dialysis patients: prevalence, measurement, outcome, and psychological determinants. Semin Dial. 2014;27(1):42-9.

22. Alkatheri AM, Alyousif SM, Alshabanah N, Albekairy AM, Alharbi S, Alhejaili FF, et al. Medication adherence among adult patients on hemodialysis. Saudi J Kidney Dis Transpl. 2014;25(4):762-8.

23. Nabolsi MM, Wardam L, Al-Halabi JO. Quality of life, depression, adherence to treatment and illness perception of patients on haemodialysis. Int J Nurs Pract. 2015;21(1):1-10.

24. Khalil AA, Darawad M, Al Gamal E, Hamdan-Mansour AM, Abed MA. Predictors of dietary and fluid non-adherence in Jordanian patients with end-stage renal disease receiving haemodialysis: a cross-sectional study. J Clin Nurs. 2013;22(1-2):127-36.

25. Jamous RM, Sweileh WM, Abu-Taha AS, Sawalha AF, Zyoud SH, Morisky DE. Adherence and satisfaction with oral hypoglycemic medications: a pilot study in Palestine. Int J Clin Pharm. 2011;33(6):942-8.

26. Jamous RM, Sweileh WM, El-Deen Abu Taha AS, Zyoud SH. Beliefs about medicines and self-reported adherence among patients with chronic illness: a study in Palestine. J Family Med Prim Care. 2014;3(3):224-9.

27. Sweileh WM, Abu-Hadeed HM, Al-Jabi SW, Zyoud SH. Prevalence of depression among people with type 2 diabetes mellitus: a cross sectional study in Palestine. BMC Public Health. 2014;14:163.

28. Sweileh WM, Ihbesheh MS, Jarar IS, Sawalha AF, Abu Taha AS, Zyoud SH, et al. Differences in medication adherence, satisfaction and clinical symptoms in schizophrenic outpatients taking different antipsychotic regimens. Curr Drug Saf. 2011;6(5):285-90

29. Sweileh WM, Ihbesheh MS, Jarar IS, Sawalha AF, Abu Taha AS, Zyoud SH, et al. Antipsychotic medication adherence and satisfaction among Palestinian people with schizophrenia. Curr Clin Pharmacol. 2012;7(1):49-55.

30. Sweileh WM, Ihbesheh MS, Jarar IS, Taha AS, Sawalha AF, Zyoud SH, et al. Self-reported medication adherence and treatment satisfaction in patients with epilepsy. Epilepsy Behav. 2011;21(3):301-5.

31. Sweileh WM, Zyoud SH, Abu Nab'a RJ, Deleq MI, Enaia MI, Nassar SM, et al Influence of patients' disease knowledge and beliefs about medicines on medication adherence: findings from a cross-sectional survey among patients with type 2 diabetes mellitus in Palestine. BMC Public Health. 2014;14:94.

32. Zyoud SH, Al-Jabi SW, Sweileh WM, Morisky DE. Relationship of treatment satisfaction to medication adherence: findings from a cross-sectional survey among hypertensive patients in Palestine. Health Qual Life Outcomes. 2013;11:191.

33. Zyoud SH, Al-Jabi SW, Sweileh WM, Wildali AH, Saleem HM, Aysa HA, et al. Health-related quality of life associated with treatment adherence in patients with hypertension: a cross-sectional study. Int J Cardiol. 2013;168(3):2981-3.

34. Zyoud SH, Al-Jabi SW, Sweileh WM, Tabeeb GH, Ayaseh NA, Sawafta MN, et al. Use of complementary and alternative medicines in haemodialysis patients: a cross-sectional study from Palestine. BMC Complement Altern Med. 2016:16:204

35. Zyoud SH, Daraghmeh DN, Mezyed DO, Khdeir RL, Sawafta MN, Ayaseh NA, et al. Factors affecting quality of life in patients on haemodialysis: a crosssectional study from Palestine. BMC Nephrol. 2016;17(1):44.

36. Green JA, Mor MK, Shields AM, Sevick MA, Arnold RM, Palevsky PM, et al. Associations of health literacy with dialysis adherence and health resource utilization in patients receiving maintenance hemodialysis. Am J Kidney Dis. 2013;62(1):73-80.

37. Kim Y, Evangelista LS, Phillips LR, Pavlish C, Kopple JD. The End-Stage Renal Disease Adherence Questionnaire (ESRD-AQ): testing the psychometric properties in patients receiving in-center hemodialysis. Nephrol Nurs J. 2010;37(4):377-93.

38. Chan YM, Zalilah MS, Hii SZ. Determinants of compliance behaviours among patients undergoing hemodialysis in Malaysia. PLoS One. 2012;7(8):e41362.

39. Al-Khattabi GH. Prevalence of treatment adherence among attendance at hemodialysis in Makah. Int J Med Sci Public Health. 2014;3(5):592-8.

40. Lee SH, Molassiotis A. Dietary and fluid compliance in Chinese hemodialysis patients. Int J Nurs Stud. 2002;39(7):695-704.

41. Sgnaolin V, Figueiredo AE. Adherence to pharmacological treatment in adult patients undergoing hemodialysis. J Bras Nefrol. 2012;34(2):109-16.

42. Sabi KA, Noto-Kadou-Kaza B, Amekoudi YE, Tsevi MC, Sylla F, Kossidze K, et al. Medication adherence of 65 patients in hemodialysis in Togo. Med Sante Trop. 2014;24(2):172-6.

43. Kelly K, Grau-Sepulveda MV, Goldstein BA, Spratt SE, Wolfley A, Hatfield V, et al. The agreement of patient-reported versus observed medication adherence in type 2 diabetes mellitus (T2DM). BMJ Open Diabetes Res Care. 2016;4(1):e000182

44. Thirumurthy H, Siripong N, Vreeman RC, Pop-Eleches C, Habyarimana JP, Sidle $J E$, et al. Differences between self-reported and electronically monitored adherence among patients receiving antiretroviral therapy in a resourcelimited setting. AIDS. 2012:26(18):2399-403.

\section{Submit your next manuscript to BioMed Central and we will help you at every step:}

- We accept pre-submission inquiries

- Our selector tool helps you to find the most relevant journal

- We provide round the clock customer support

- Convenient online submission

- Thorough peer review

- Inclusion in PubMed and all major indexing services

- Maximum visibility for your research

Submit your manuscript at www.biomedcentral.com/submit 